\title{
Characterization of Norovirus RNA replicase for in vitro amplification of RNA
}

\author{
Hidenao Arai ${ }^{1}$, Koichi Nishigaki ${ }^{1}$, Naoto Nemoto ${ }^{1}$, Miho Suzuki $^{1}$ and Yuzuru Husimi ${ }^{2 *}$
}

\begin{abstract}
Background: The isothermal amplification of RNA in vitro has been used for the study of in vitro evolution of RNA. Although $\mathrm{Q} \beta$ replicase has been traditionally used as an enzyme for this purpose, we planned to use norovirus replicase (NV3D ${ }^{\mathrm{pol}}$ ) due to its structural simplicity in the scope of in vitro autonomous evolution of the protein. Characteristics of the enzyme NV3D ${ }^{\text {pol }}$ in vitro were re-evaluated in this context.

Results: NV3D ${ }^{\text {pol }}$, synthesized by using a cell-free translation system, represented the activities which were reported in the previous several studies and the reports were not fully consistent each other. The efficiency of the initiation of replication was dependent on the $3^{\prime}$-terminal structure of single-stranded RNA template, and especially, NV3D ${ }^{\text {pol }}$ preferred a self-priming small stem-loop. In the non-self-priming and primer-independent replication reaction, the presence of -CCC residues at the $3^{\prime}$-terminus increased the initiation efficiency and we demonstrated the one-pot isothermal RNA (even dsRNA) amplification by 16 -fold. NV3D ${ }^{\text {pol }}$ also showed a weak activity of elongation-reaction from a long primer. Based on these results, we present a scheme of the primer-independent isothermal amplification of RNA with NV3D ${ }^{\text {pol }}$ in vitro.
\end{abstract}

Conclusions: NV3D ${ }^{\text {pol }}$ can be used as an RNA replicase in in vitro RNA + protein evolution with the RNA of special terminal sequences.

Keywords: RNA-dependent RNA polymerase, RNA replication, Isothermal RNA amplification, in vitro evolution

\section{Background}

In vitro evolution of RNA has been performed with a given replicase [1-3] or with a given RNA polymerase and a given reverse transcriptase [4-6]. In vitro evolution of RNA having a gene region encoding the replicase, that is, in vitro evolution of RNA with an evolvable replicase [7] is a next step approaching to synthetic biology on an origin of life. It may be one of the most fundamental experiments of in vitro evolution of a protein. In vitro evolution of a protein has to be coupled with in vitro evolution of its gene and usually is performed with a given translation system. If a synthetic biologist wishes to reconstruct the phenomenon of the origin of life, he should use primitive translation system which can evolve to high efficient system, but such a translation system is not available.

\footnotetext{
* Correspondence: husimi@mail.saitama-u.ac.jp

${ }^{2}$ Innovative Research Organization, Saitama University, 255 Shimo-Okubo, Sakura-ku, Saitama 338-8570, Japan

Full list of author information is available at the end of the article
}

Coupling a protein evolution and its gene evolution is realized by a phenotype-genotype linking strategy in the selection process. There are four types of the strategy; ribozyme-type, virus-type, cell-type and external intelligence-type. The ribozyme-type is the strategy of phenotype-genotype linking by carrying both on an RNA $[8,9]$. The virus-type is the strategy by binding a protein to its gene $[10,11]$. The cell-type is the strategy by enclosing a protein and its gene in a compartment [7]. External intelligence-type is the strategy by measuring and picking the fittest protein [12].

In vitro evolution experiments can be classified into two categories; artificial selection-type and natural selection-type. The former is called directed evolution, in which the fitness measure is set by the experimenter. The fitness of the latter experiment is the specific growth rate. PCR is most convenient amplification method in the former experiments, but cannot be used in the latter experiments. One-pot isothermal amplification method is convenient in the latter, because a flow reactor experiment is possible in principle and a serial 
transfer experiment is easily performed as an approximation of the flow reactor experiment. Examples of the one-pot isothermal amplification are $Q \beta$ replicase method [1], 3SR [4], NASBA [5], RNA-Z [6], etc.

$\mathrm{Q} \beta$ RNA replicase is from an RNA phage $\mathrm{Q} \beta$ of E.coli and is a hetero-tetramer, in which only $\beta$ subunit is encoded in the viral genome and other three subunits (EF-Tu, EF-Ts and S1) are recruited from the host-cell translation machinery [13]. For the effective replication of viral genome RNA, it requires a host factor $\mathrm{Hfq}$, which binds to the specific site of the RNA and recruits the replicase [14]. When the isothermal amplification of the genomic RNA was performed in a test tube, a parasitic short RNA called RQ RNA emerged and it made the amplification of genomic RNA difficult [15]. Yomo and the coworkers demonstrated that the compartmentalization of the reaction solution into a water-in-oil emulsion inhibits the growth of the parasite [16].

Yomo's compartment method is just a cell-type strategy of phenotype-genotype linking and was applied to an experiment of the coupled RNA/replicase evolution [16]. We are planning an experiment of the coupled RNA/replicase evolution by using an isothermal RNA amplification and a virus-type strategy called in vitro virus method or mRNA display $[10,11]$. This "in vitro virus" will evolve autonomously in a flow reactor. $Q \beta$ RNA replicase is not adequate for our purpose because it must recruit three proteins from the cell-free replication system and this situation makes population growth dynamics very complex in the test tube containing the cell free translation system. Norovirus RNA replicase (RNA-dependent RNA polymerase; $\mathrm{NV} \mathrm{D}^{\mathrm{pol}}$ ) is a candidate for our in vitro virus, because it consists of a single polypeptide chain and its molecular weight is not so large (56 kDa).

There are several preceding reports on the characteristics of various modes of RNA replication catalyzed by the $\mathrm{NV} \mathrm{D}^{\mathrm{pol}}$ in vitro [17-20]. They reported on the activity of making of double-strand RNA through complementary strand polymerization on a single strand template with and without a primer, the activity of strand dissociation replication, the activity of making of a hairpin through self-priming and also the terminal nucleotidyl transferase (TNT) activity. Their reports were not consistent with each other.

Therefore we re-examined the activities of $\mathrm{NV} \mathrm{D}^{\text {pol }}$ in vitro in order to investigate whether we can use this enzyme as an RNA replicase in evolution experiments in vitro, instead of $\mathrm{Q} \beta$ replicase.

\section{Results}

\section{Preparation of NV3D ${ }^{\text {pol }}$}

The gene of our NV3D ${ }^{\text {pol }}$ was a gift from BML Inc., that is, it was same as Ref. [19]. After construction of pTDNV3D ${ }^{\text {pol }}$-strep, we sequenced it and confirmed ours was triple mutant at amino acid sequence level from the sequence in Ref. [19], which was different from the sequence in Ref. [16] (See Additional file 1: Figure S1). As shown in Figure 1A, a band corresponding to about

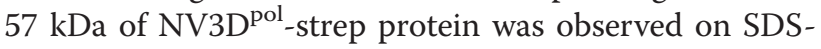
PAGE. From the incorporation of FluoroTect ${ }^{\mathrm{TM}}$ Green $_{\text {Lys }}$ tRNA into the protein during the cell-free translation, only a sharp single band was detected under a fluorescence detection mode (Figure 1B). Therefore, NV3D ${ }^{\mathrm{pol}}$ strep protein was synthesized correctly in the insect cell-free translation system. $\mathrm{NV}^{\mathrm{D}} \mathrm{D}^{\mathrm{pol}}$-strep protein mo-
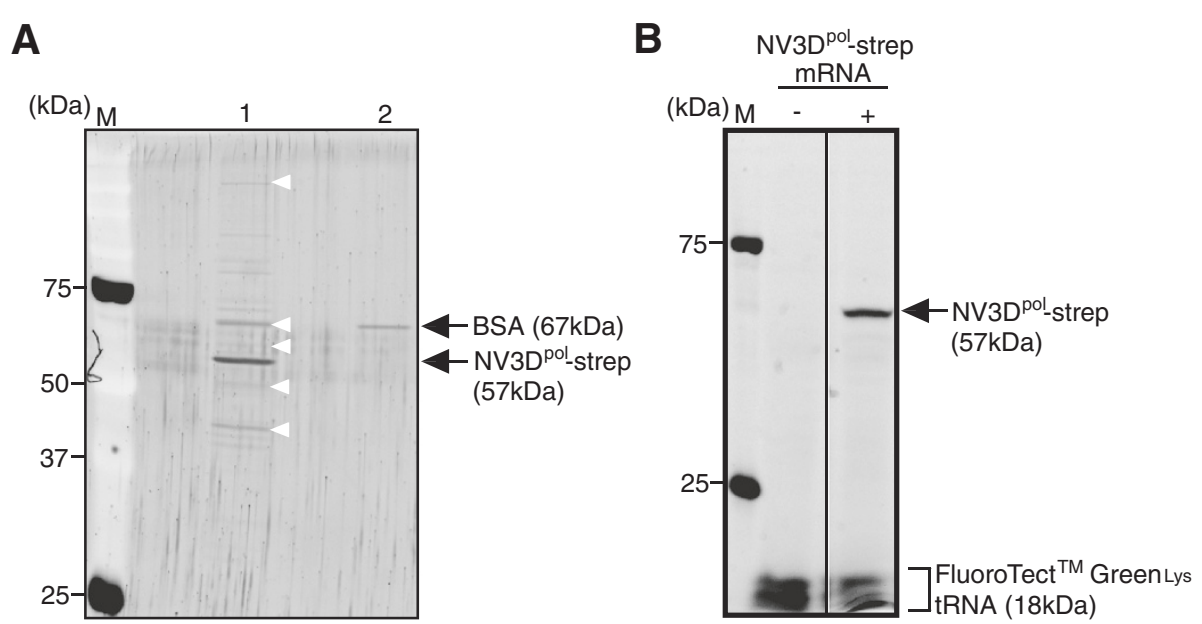

Figure 1 Preparation of NV3D ${ }^{\text {pol }}$. (A) SDS-PAGE analysis of NV3D ${ }^{\text {pol }}$-strep synthesized in the cell-free translation system and purified with StrepTactin Superflow Plus purification system (Lane1), and BSA (Lane2). M; protein molecular marker (Precision Plus Protein ${ }^{\mathrm{TM}}$ Dual Color Standards, Bio-Rad). SDS-PAGE was detected with SYPROruby (Invitrogen) staining. White arrowheads indicate the proteins from BSA solution (TaKaRa) used as carrier protein. (B) Same as (A) except incorporation of FluoroTect ${ }^{\mathrm{TM}}$ Green $_{\text {Lys }}$ tRNA into NV3D ${ }^{\text {pol }}$-strep during the cell-free translation reaction and detected under a fluorescence detection mode. Translation reaction was run with or without the NV3D ${ }^{\text {pol }}$-strep mRNA. 
diied with Strep-tag II [21] at the C-terminus was able to be highly purified with Strep-tactin affinity chromatography (Figure 1A). In Figure 1A lane1, white arrowhead indicates the protein bands taken from BSA solution (TaKaRa). As shown in Additional file 2: Figure S2, NV3D ${ }^{\text {pol }}$ had an RNA-dependent RNA synthesis activity under the excess BSA condition. Therefore, NV3D ${ }^{\text {pol }}$ prepared here was not affected with contaminated proteins.

\section{RNA amplification reaction with NV3D ${ }^{\text {pol }}$}

Four kinds of single stranded RNA (ssRNA) of which sequences were different in the 3'-terminal three nucleotides (Figure 2A, underlined) were used as an RNA template. As shown in Figure 2B, when $\mathrm{NV}^{\mathrm{B}} \mathrm{D}^{\mathrm{pol}}$ and the RNA template were incubated at $30^{\circ} \mathrm{C}$ and analyzed on a denaturing PAGE, two reaction products of $50 \mathrm{nts}$ and 90-100 nts were amplified with time. In the case of Temp(GGG-CCC) and Temp(GGG-CCA), RNA templates (50 nts) were amplified as indicated with black arrow in Figure 2B (i, iii) (see Additional file 3: Figure $\mathrm{S} 3 \mathrm{~A}$, closed circle and triangle). In the case of Temp (GGG-GGG) and Temp(GGG-UAC), RNA templates were amplified slightly (see Additional file 3: Figure S3A, closed diamond and square). In the case of Temp(GGGCCC), when the amplified product was treated with ribonuclease S1, it was not digested (shown in Additional file 4: Figure S4). Thus, the amplified products were a double stranded RNA (dsRNA). $\mathrm{NV} \mathrm{D}^{\mathrm{pol}}$ made a dsRNA from an ssRNA in a primerindependent manner and amplified it. This result is consistent with the report by Rohayem et al. [17,18] and Fukushi et al. [19]. In addition to the amplification product of 50 nts, amplification products between 90 and 100 nts were observed in the case of Temp(GGG-GGG), Temp(GGG-CCA) and Temp(GGG-UAC) (Figure 2B (ii, iii, iv) indicated by asterisks and arrow heads). We show Additional file 3: Figure S3B as a non-denaturing PAGE version of Figure $2 \mathrm{~B}$ which was from denaturing PAGE. In Additional file 3: Figure S3B, all the templates ((i) Temp(GGG-CCC), (ii) Temp(GGG-GGG), (iii) Temp (GGG-CCA) and (iv) Temp(GGG-UAC)) gave growing band near 50 bp dsRNA size. For (i), it was confirmed to be actually dsRNA by $\mathrm{S} 1$ nuclease treatment (Additional file 4: Figure S4). In Figure 2B, for (i), the growing band was simply 50 nts ssRNA, but for (ii) - (iv), the growing bands were not only 50 nts, but also $90-100$ nts ssRNA. The possible explanation is as follows: the growing band near 50 bp dsRNA in Additional file 3: Figure S3B (ii) - (iv) corresponds to hairpin RNA (major component) (plus dsRNA (minor component)). These must be self-priming products starting from a short stem-loop at 3'-terminus. In fact in each sequence of (ii) - (iv) we found such a small potential stem-loop at 3'-terminus (shown in Additional file 5: Figure S5), but in the sequence of (i) we did not find any small potential stem-

\section{A}

(i) Temp(GGG-CCC): 5' GGGAAUAAGAUUUCACAGUUCAGAGAGACAUUAAGUUGUUGUUGUUGCCC $3^{\prime}$

(ii) Temp(GGG-GGG): 5'GGGAAUAAGAUUUCACAGUUCAGAGAGACAUUAAGUUGUUGUUGUUGGGG 3 '

(iii) Temp(GGG-CCA): 5' GGGAAUAAGAUUUCACAGUUCAGAGAGACAUUAAGUUGUUGUUGUUG $\underline{\underline{G C A}} 3^{\prime}$

(iv) Temp(GGG-UAC): 5' GGGAAUAAGAUUUCACAGUUCAGAGAGACAUUAAGUUGUUGUUGUUGUAC 3'

\section{B}

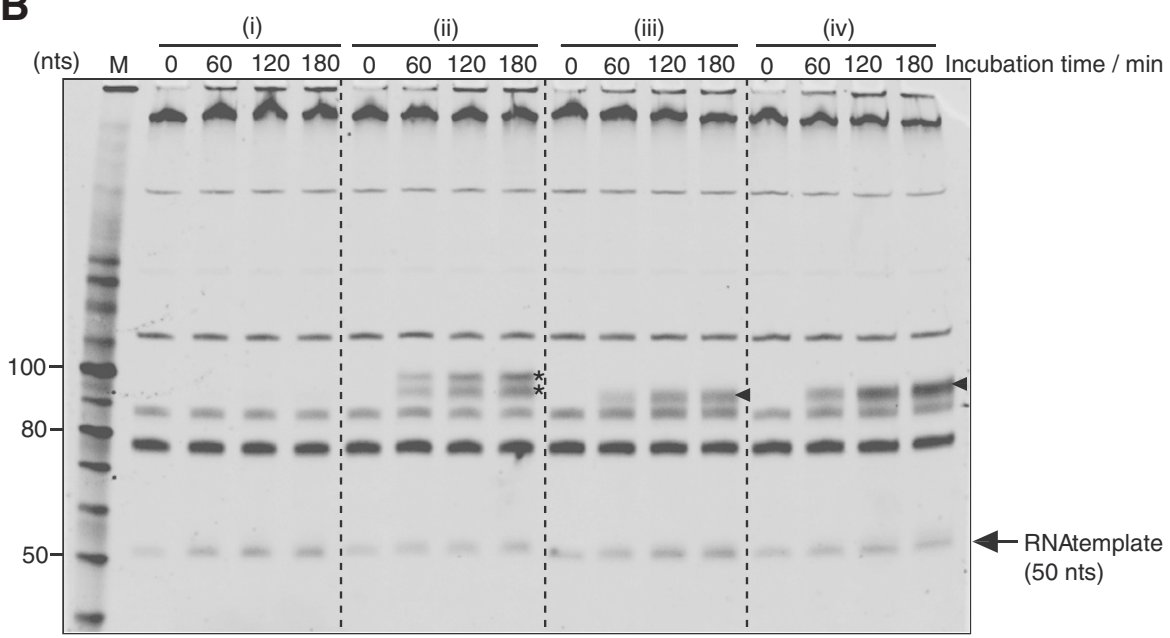

Figure 2 Primer-independent RNA synthesis on RNA templates with NV3D ${ }^{\text {pol }}$. (A) The sequence of RNA templates. (B) NV3D ${ }^{\text {pol }}(5$ pmol) was incubated with (i) Temp(GGG-CCC), (ii) Temp(GGG-GGG), (iii) Temp(GGG-CCA) or (iv) Temp(GGG-UAC) (5 pmol each), and sampled at 0, 60, 120, 180 min respectively (reaction volume $=20 \mu \mathrm{L}$ ). Each reaction products were separated on an $8 \mathrm{M}$ urea denaturing 10\% PAGE, and imaged with Fx imager after SYBRgreenll staining. M; 10 bp DNA step ladder marker (Promega). Black arrow indicates the mobility of each RNA templates (50 nts). For bands indicated by asterisk and short arrows, see text. Other constant bands were from components of cell-free translation system. 
loop at 3'-terminus. This result is consistent with the reports by Belliot et al. [20] and Wei et al. [22].

The time-course of the primer-independent amplifica-

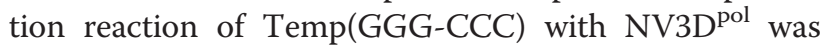
measured and detected on a denaturing PAGE (Figure 3A) or a non-denaturing PAGE (Figure 3B), and quantified (Figure 3C). As shown in Figure 3B, dsRNA of about $50 \mathrm{bp}$ was amplified with time on a nondenaturing PAGE. In the previous studies [17-19], a time-course measurement of amplification reaction was not reported. As shown in Figure 3C closed square, when the amplification reaction was performed with 11 pmol of NV3D ${ }^{\mathrm{pol}}$ and $10 \mathrm{pmol}$ of Temp(GGG-CCC) RNA, the RNA template was amplified linearly up to $60 \mathrm{~min}$ and reached at plateau near $240 \mathrm{~min}$. On the denaturing PAGE (Figure 3A), about $160 \mathrm{pmol}$ of ssRNA (50 nts) was detected at 240 min, thus NV3D ${ }^{\text {pol }}$ amplified 10 pmol of ssRNA to about 80 pmol of dsRNA isothermally in a test tube (16-fold amplification). When 4 pmol of NV3D ${ }^{\mathrm{pol}}$ and $8 \mathrm{pmol}$ of Temp(GGG-CCC) RNA were incubated and quantified on the denaturing PAGE, the amplification curve was shown by closed circle in Figure $3 \mathrm{C}$. In the both amplification reaction, the concentration of Temp(GGG-CCC) RNA was constant $(0.25 \mu \mathrm{M})$. As shown in Figure 3C, the amplification efficiency was depended on the concentration of NV3D pol (closed square versus closed circle). Activity of our enzyme varied between different lots. But within the same lot the activity was fairly reproducible as shown in
Figure 3C (closed circle). Thus comparative studies using enzyme from the same lot were meaningful.

\section{3 '-terminal sequence dependence of initiation of ssRNA replication in a primer-independent manner}

Rohayem et al. [17] indicated the following two points. First, NV3D ${ }^{\mathrm{pol}}$ initiated the replication on an oligo cytidine. Second, NV3D ${ }^{\text {pol }}$ added some cytidines at the 3'terminus of the synthesized strand. From these results, they suggested that NV3D ${ }^{\mathrm{pol}}$ prefers a C-stretch for the initiation of replication in primer-independent manner.

We investigated the number of cytidine for the efficient initiation of replication in primer-independent manner. Temp(GGG-UUC), Temp(GGG-UCC), Temp (GGG-CCC) or Temp(GGG-CCCC) RNA, which have from 1 to 4 cytidine(s) at their 3'-terminus (shown in Figure 4A) and have no small stem-loop at their 3'-terminus, were incubated with $\mathrm{NV} 3 \mathrm{D}^{\mathrm{pol}}$ at $30^{\circ} \mathrm{C}$. The time-course measurements of each case were analyzed on a denaturing PAGE (Figure 4B and C) and quantified (Figure 4D and E). At least two cytidines were necessary for the amplification. And in the case of Temp(GGGCCC) RNA, the initiation efficiency of replication seemed to be saturated at three cytidines.

We next measured the time-course of amplification reaction using two kinds of 479 nts RNA template, named TD257-735 RNA and TD257-735g734c RNA. These RNA templates (derived from pTD1 expression vector [23]) were not from norovirus genome. Thus the

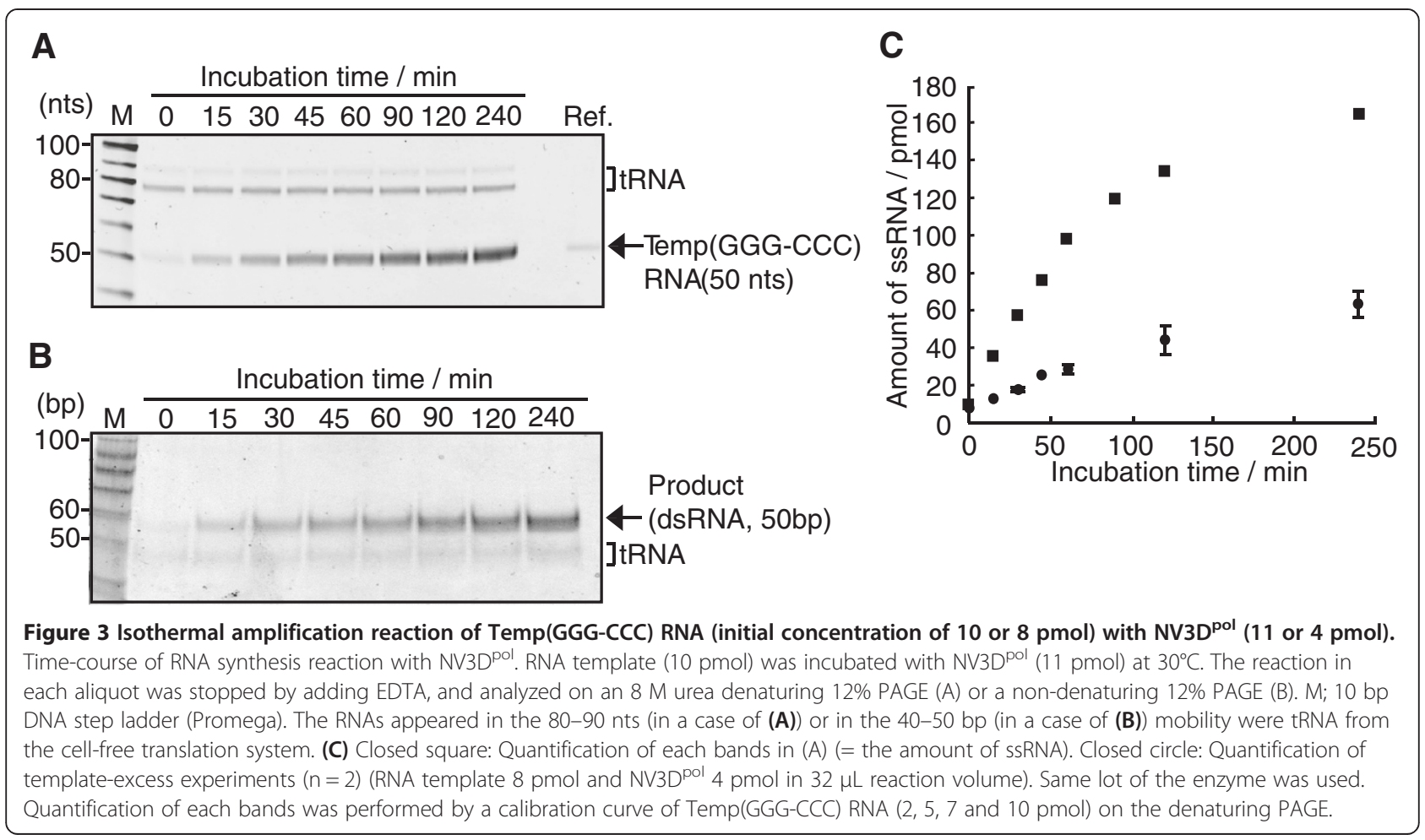




\begin{abstract}
A
(i) Temp(GGG-UUC): 5' GGGAAUAAGAUUUCACAGUUCAGAGAGACAUUAAGUUGUUGUUGUUGUUC 3'

(ii) Temp(GGG-UCC): 5' GGGAAUAAGAUUUCACAGUUCAGAGAGACAUUAAGUUGUUGUUGUUGUCC $3^{\prime}$

(iii) Temp(GGG-CCC): 5' GGGAAUAAGAUUUCACAGUUCAGAGAGACAUUAAGUUGUUGUUGUUGCCC 3'

(iv) Temp(GGG-CCCC): 5' GGGAAUAAGAUUUCACAGUUCAGAGAGACAUUAAGUUGUUGUUGUUGCCCC 3'
\end{abstract}

B

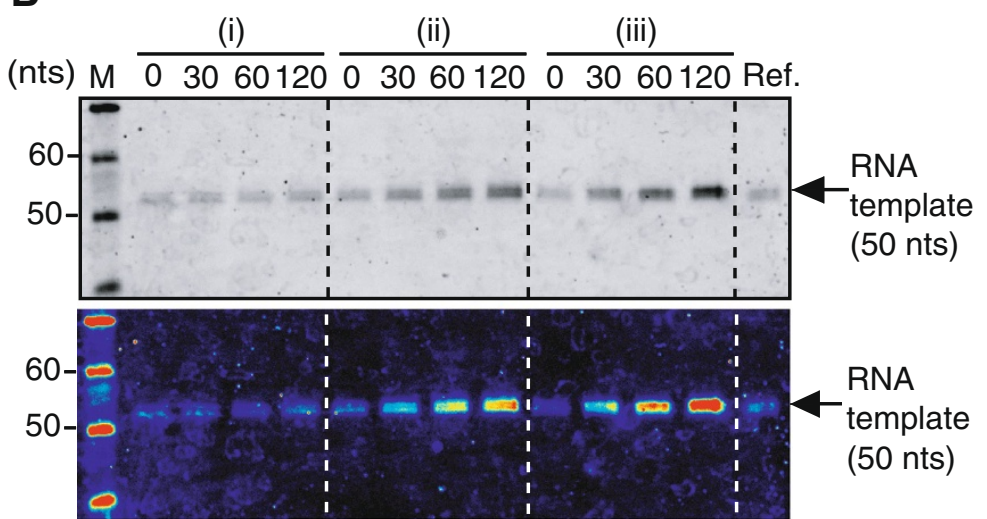

C

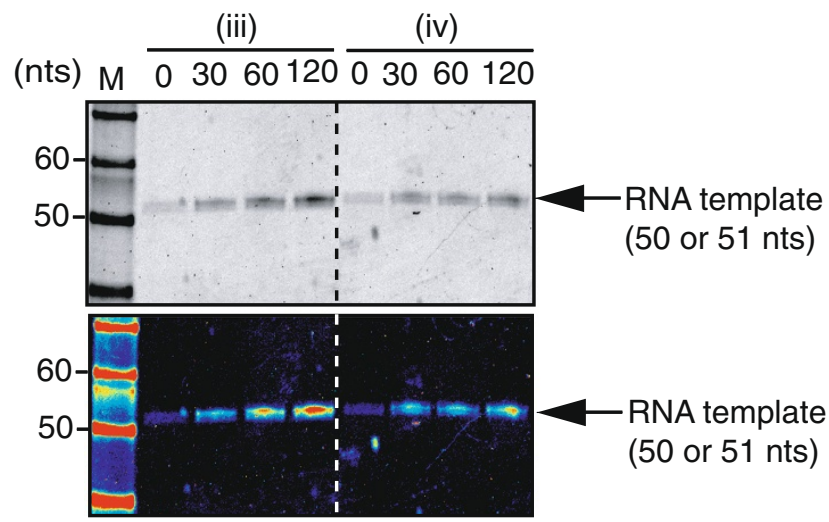

D

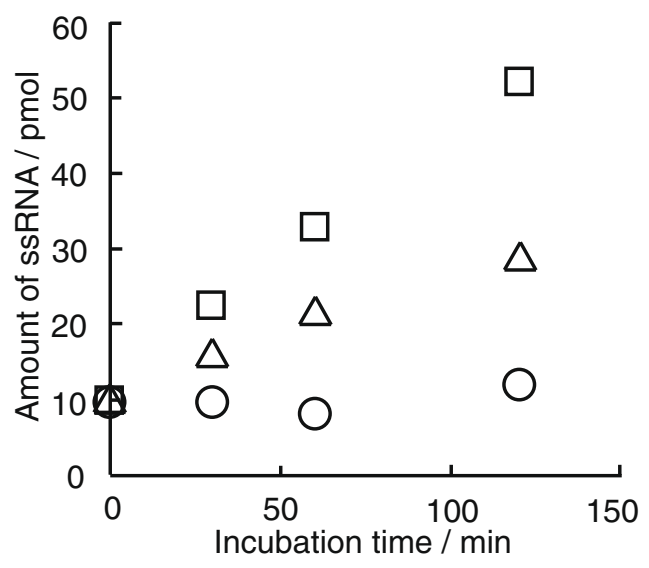

E

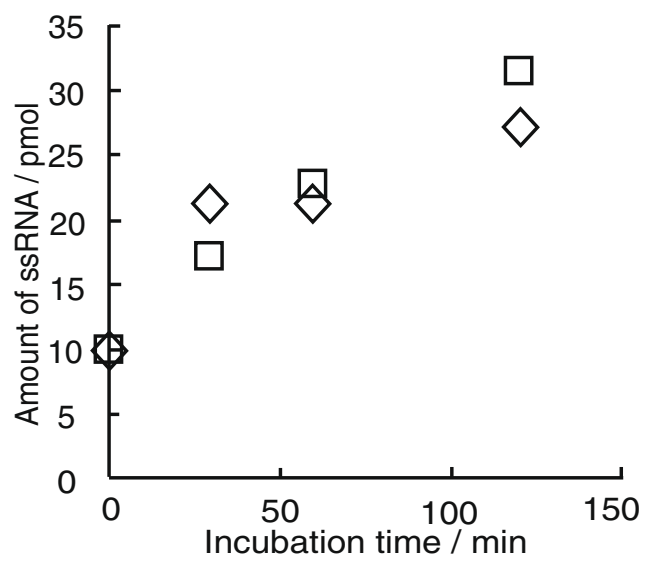

Figure 4 Effect of the $3^{\prime}$-terminal sequence of template for the initiation efficiency of RNA replication. (A) The sequence of Temp (GGG-UUC), Temp (GGG-UCC), Temp (GGG-CCC) and Temp (GGG-CCCC). (B) and (C) NV3D pol (10 pmol) and each RNA templates (10 pmol) were incubated at $30^{\circ} \mathrm{C}$ and sampled at 0,30,60, $120 \mathrm{~min}$ (reaction volume $=40 \mu \mathrm{L}$ ). Aliquots were analyzed on an $8 \mathrm{M}$ urea denaturing $10 \% \mathrm{PAGE}$ and imaged with Fx imager after SYBRgreenll staining. Color-coded images were shown at the bottom. M; 10 bp DNA step ladder marker (Promega). Ref.; Temp (GGG-CCC) RNA. (D) and (E) Quantification of the amount of RNA strands from the denaturing PAGE (B) and (C), respectively. RNA quantification method was same as in Figure 3. Circle; Temp(GGG-UUC), triangle; Temp (GGG-UCC), square; Temp (GGG-CCC) and diamond; Temp (GGG-CCCC), respectively.

initiation efficiency of these RNA templates is not related to NV3D ${ }^{\mathrm{pol}}$ specificity. And the 3'-terminal structure of both templates is predicted to be a free single strand. TD257-735g734c RNA was generated by substituting -CCGC-3' at the 3'-terminal region of TD257735 RNA with --CCCC-3'. The reaction aliquots were analyzed on a non-denaturing PAGE (Figure 5A and B), and quantified (Figure 5C). By substituting the 3'-terminal sequence to a C-stretch (from --CCGC-3' of TD257-735 RNA to -CCCC-3' of TD257-735g734c
RNA), the amplification efficiency was increased remarkably.

While Rohayem et al. [17] showed that NV3D pol does not have an RNA synthesis activity on poly (A)-tail, Fukushi et al. [19] indicated that NV3D ${ }^{\text {pol }}$ has this activity. In order to re-examine this activity, we synthesized an RNA bearing an A-stretch of $22 \mathrm{nts}$ at the 3'-terminus (named TD257-735- $\mathrm{A}_{22}$ ), and incubated with $\mathrm{NV} 3 \mathrm{D}^{\mathrm{pol}}$. Our NV3D ${ }^{\mathrm{pol}}$ showed a slight activity to poly(A)-tail and the amplified 


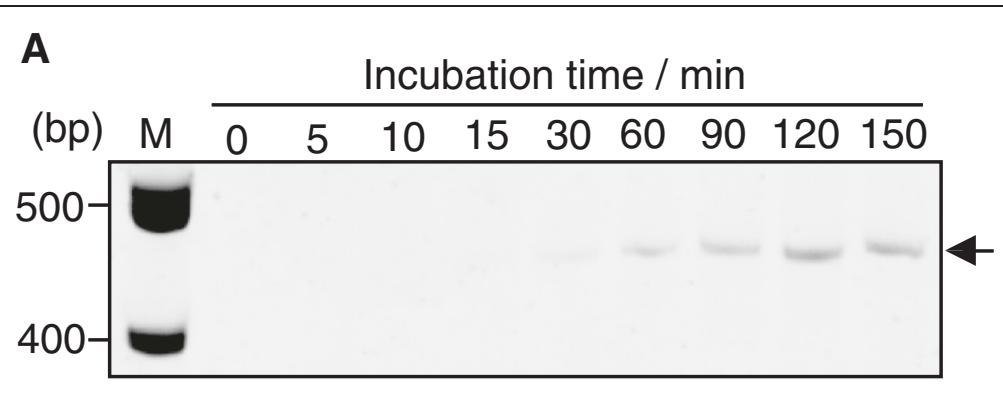

B

Incubation time / min

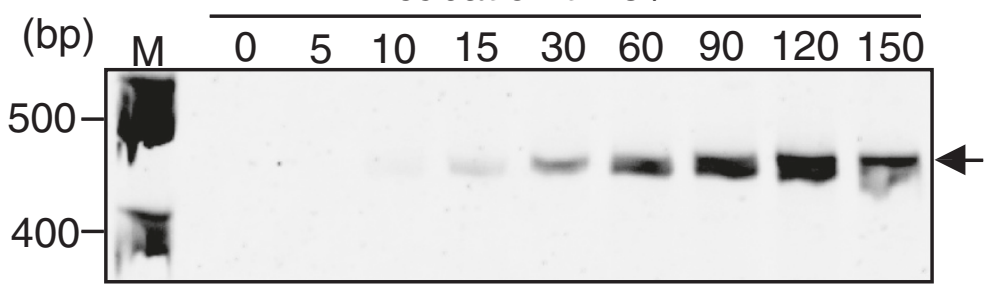

C

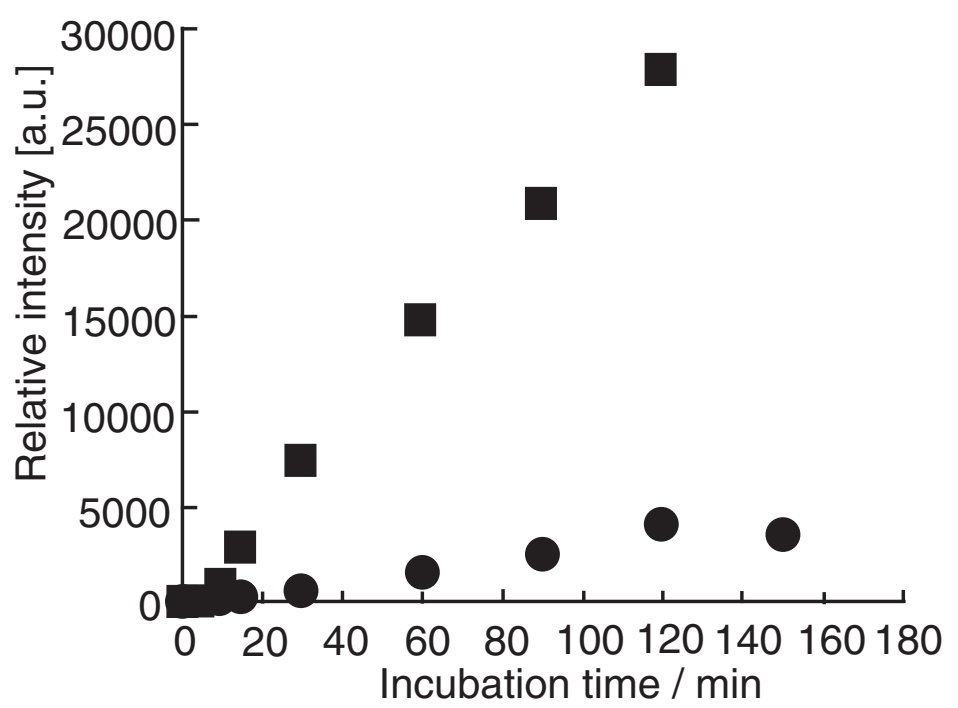

Figure 5 Effect of the $\mathbf{3}^{\prime}$-C-stretch of a long template for the initiation efficiency of RNA replication. Two kinds of RNA template (TD257-735 (A) and TD257-735g734C (B) (0.4 pmol) were incubated with NV3D ${ }^{\mathrm{pol}}$ (8 pmol), respectively (reaction volume $=20 \mu \mathrm{L}$ ), and analyzed on a non-denaturing 5\% PAGE. M; 100 bp DNA ladder marker (Promega). (C) The PAGE images were visualized by SYBRgreenll staining and quantified with reference to $0 \mathrm{~min}$ as the standard. The band intensities of amplified dsRNA were plotted. Closed circle; TD257-735. Closed square; TD275-735g734c.

products appeared after $30 \mathrm{~min}$ (Additional file 6: Figure S6).

\section{Terminal nucleotidyl transferase activity and replication of dsRNA}

In the reaction using Temp(GGG-CCC), the amplified product, sampled at $240 \mathrm{~min}$ of incubation, reaching at plateau, was sequenced. The replicated complementary RNA (RNA(-)) was reverse-transcribed into cDNA using Y-ligation technique shown in Methods. The determined sequences were shown in Table 1 . We could observe the addition of 1-3 cytidines at the 3'-terminus of RNA(-). But $50 \%$ of the sequenced $\mathrm{RNA}(-)$ had no added cytidine at the 3'-terminus. We could also observe the addition of two nucleotides of adenosine or guanosine.

It was reported that the sticky end formed by this TNT activity is favourable for the next round replication of the dsRNA [17]. We re-examine this point. Two kinds of RNA template (shown in Figure 6A and B) were incubated with $\mathrm{NV} \mathrm{D}^{\text {pol }}$ at $30^{\circ} \mathrm{C}$ and analyzed on 
Table 13 '-terminal sequence of replication products under potential TNT activity

\begin{tabular}{llc}
\hline TNT activity & $\begin{array}{l}\text { 3'-terminal } \\
\text { sequence of cRNA }\end{array}$ & $\begin{array}{c}\text { Number of } \\
\text { clones }\end{array}$ \\
\hline TNT less & 3' CCCUUA-- & 11 \\
TNT 1 nts (C) & 3' CCCCUUA-- & 3 \\
TNT 2 nts (CC) & 3' CCCCCUUA-- & 3 \\
TNT 3nts (CCC) & 3' CCCCCCUUA-- & 1 \\
TNT 2nts (AA) & 3' AACCCUUA-- & 1 \\
TNT 2nts (GG) & 3' GGCCCUUA-- & 1 \\
Deletion, insertion & Others & 2 \\
\hline
\end{tabular}

The result of 3 -terminal sequencing of amplified products $(n=22)$ in the reaction using Temp(GGG-CCC) shown in Figure 3, sampled at $240 \mathrm{~min}$ of incubation. non-denaturing PAGE. The secondary structures of these two RNA templates at $30^{\circ} \mathrm{C}$ predicted by Mfold [24] were shown in Figure 6B. Mfold predicted many other structures, but the stem-end (3'end and 5'end hybrid) structures were almost always conserved, namely, the probability of other 3' structures was less than $0.03 \%$. Thus these two RNAs are able to be models of dsRNAs made in the first cycle replication of an ssRNA template (e.g. Temp(GGG-CCC) with or without TNT activity. As shown in Figure $6 \mathrm{C}$, the band at about 50 bp was amplified in the case of Temp(GGG-UCCC), but it was not in the case of Temp(GGG-UCCCC). It was suggested that $\mathrm{NV} \mathrm{D}^{\mathrm{pol}}$ replicates a blunt end dsRNA preferably rather than a sticky end dsRNA.

\section{A}

(i) Temp(GGG-UCCCC):

5' GGGAAUAAGAUUUCACAGUUCAGAGAGACAUUAAGUUGUUGUUGUUCCCC 3'

(ii) Temp(GGG-UCCC):

5' GGGAAUAAGAUUUCACAGUUCAGAGAGACAUUAAGUUGUUGUUGUUCCC 3'

\section{B}

(i)

(ii)

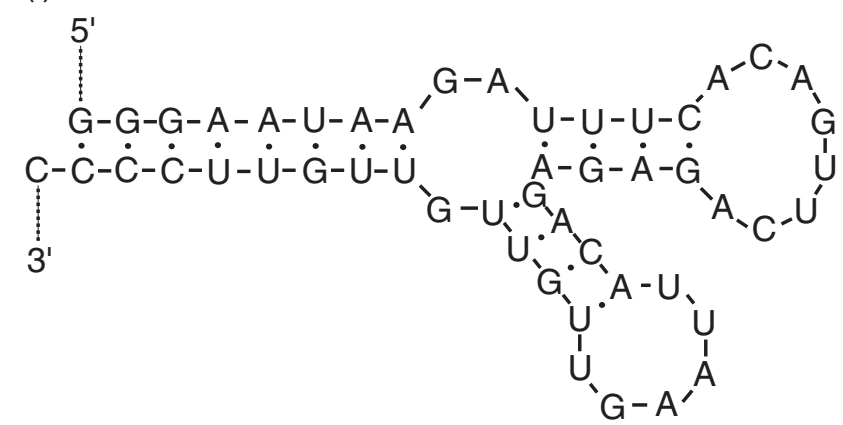

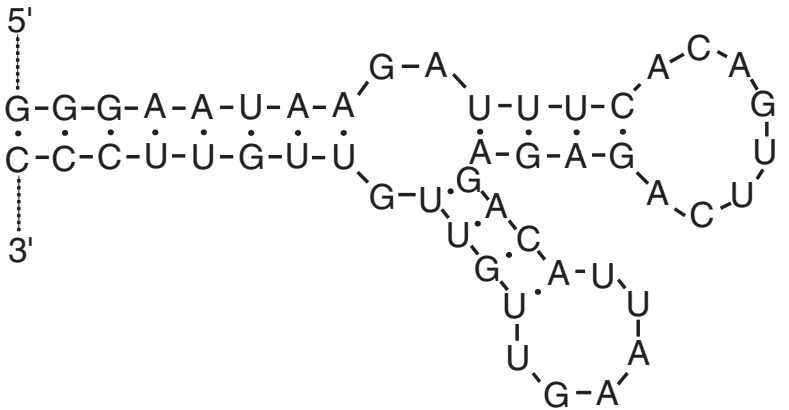

C

(i)

(ii)

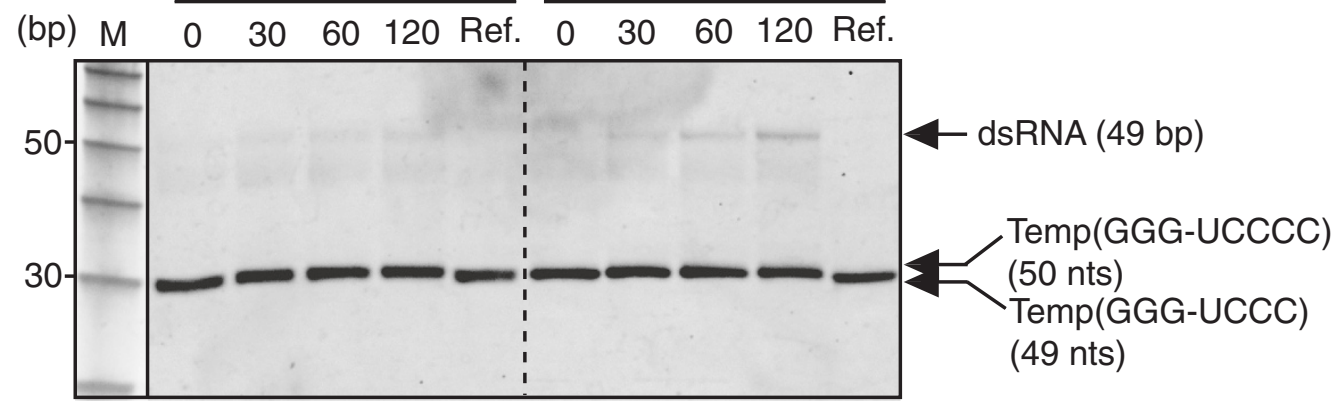

Figure 6 Effect of the terminal structure of dsRNA for the initiation of RNA replication. Two kinds of RNA template (10 pmol) ((i) Temp (GGG-UCCCC) and (ii) Temp(GGG-UCCC) (A)), of which secondary structures were predicted by Mfold (B), were incubated with NV3D ${ }^{\text {pol }}$ (4 pmol), respectively (reaction volume $=40 \mu \mathrm{L}$ ), and analyzed on a non-denaturing 10\% PAGE. The PAGE image was visualized by SYBRgreenll staining (C). M; 10 bp DNA step ladder (Promega). Ref; both RNA templates were electrophoresed as references. Mfold predicted many other structures, but the stem-end (3'end and 5'end hybrid) structures were almost always conserved, namely, the probability of other $3^{\prime}$ structures (for (i), first appearance as \#7 stable structure $(\Delta \mathrm{G}$ of \#1, \#2,-, and -\#7 structures were $-12.83,-11.08,-10.49,-10.10,-9.39,-8.52$, and $-7.99 \mathrm{kcal} / \mathrm{mol}$, respectively) was less than $0.03 \%$. 


\section{Isothermal amplification of a long RNA}

To observe the exponential phase in the isothermal amplification of comparatively long RNA with NV3D ${ }^{\text {pol }}$, TD257-735g734c RNA and NV3D ${ }^{\text {pol }}$ were incubated at the ratio of $1: 20$ in a reaction tube. Each aliquot was analyzed on a non-denaturing PAGE followed by the staining with SYBRgreenII and quantified (Figure 7). The initial RNA template (ssRNA) of $100 \mathrm{fmol}$ was amplified to $250 \mathrm{fmol}$ of dsRNA plus $100 \mathrm{fmol}$ ssRNA in 240 min (6-fold amplification). The initial apparently exponential phase was observed reproducibly.

\section{Primer extension replication}

Rohayem et al. [17] showed the primer extension replication with $\mathrm{NV} \mathrm{D}^{\text {pol }}$, but Fukushi et al. [19] suggested the enzyme does not have such an activity. We examined the activity as follows. A RNA template, Temp (GGG-CCC), hybridized with a RNA primer (16 nts) at the 3'-terminal region was incubated with $\mathrm{NV} \mathrm{D}^{\mathrm{pol}}$ and NTPs. Here, the 5'-terminus of RNA primer was modified with FITC to trace whether NV3D ${ }^{\text {pol }}$ elongates the RNA primer. That is, 5 pmol RNA template and 10 pmol RNA primer were hybridized, and then mixed with 4 pmol of $N V 3 D^{\mathrm{pol}}$ and incubated at $30^{\circ} \mathrm{C}$. As a control, primer-independent RNA synthesis reaction of Temp (GGG-CCC) RNA with NV3D ${ }^{\mathrm{pol}}$ was performed at the same time. The reaction products were analyzed on a non-denaturing PAGE or an $8 \mathrm{M}$ urea denaturing PAGE, and imaged (shown in Figure 8 and Additional file 7:

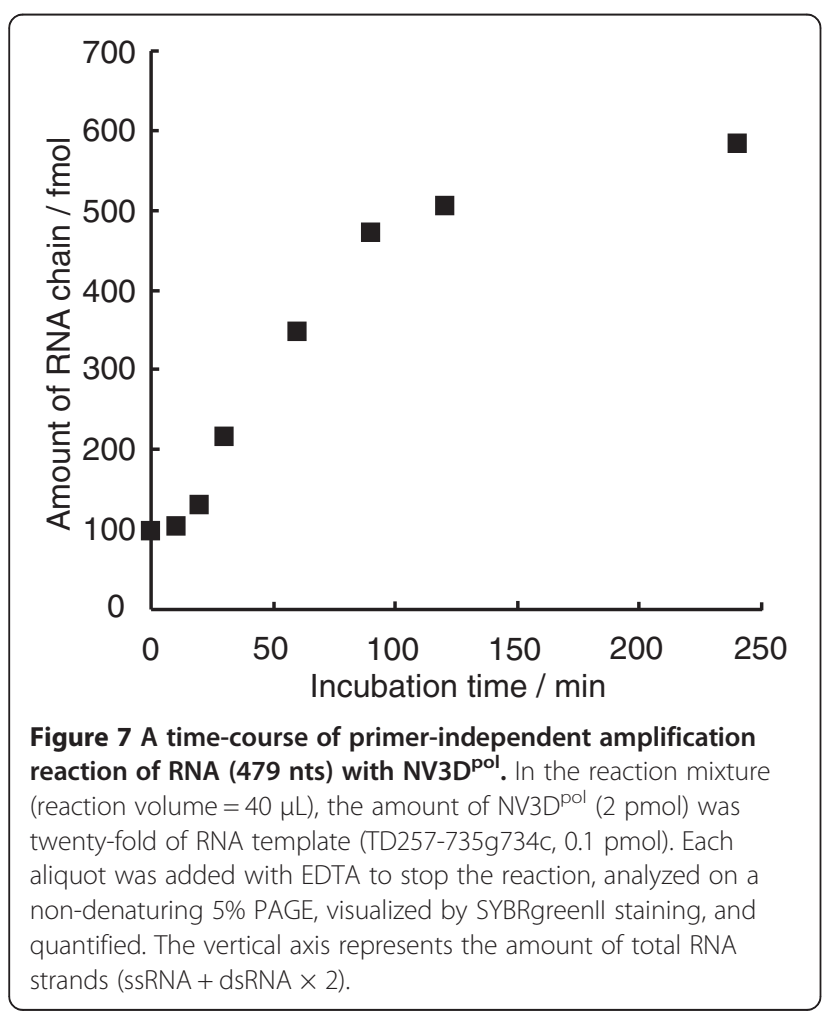

Figure S7). The dsRNA generated with $\mathrm{NV} \mathrm{D}^{\mathrm{pol}}$ was indicated by arrowhead in Figure 8B, lane2. In Figure 8C, lane1, the band indicated with arrowhead, which was detected with FITC fluorescence was about same molecular weight with dsRNA generated in a primerindependent manner (detected in lane 2 in Figure 8B, and not detected in lane 2 in Figure $8 \mathrm{C}$ ). Therefore, this product was a dsRNA generated in the primerdependent manner with NV3D ${ }^{\text {pol }}$.

\section{Discussion}

\section{Initiation reaction}

When a small stem-loop structure can be formed at 3 '-terminus, the self-priming is more favorable initiation reaction for an ssRNA template than the primerindependent manner as seen in Figure $2 \mathrm{~B}$ and Additional file 3: Figure S3B. For (iii), 3'-terminal -CA forms a hairpin stem with -UG- at upstream. For (iv), 3'-terminal -AC forms a hairpin stem with -GU- at upstream. As the template contains -GUU- repeat at 3'-terminal region, several hybridization sites can be expected. The fact that there was only one band of double length shows $\mathrm{NV} \mathrm{D}^{\mathrm{pol}}$ recognizes small loop size ( 3 for (iii), 4 for (iv)).

In this context we comment the self-priming case by Belliot et al. [20], and Wei et al. [22]. They used an RNA template of which 3'-terminal sequence is --GAU CCAAGCUUACGUACGCG-3' (the sequence showed in italics is a part of cutting site of $M l u \mathrm{I}$ restriction enzyme) and got a double length replication product. They explained it is the result of the back-priming at MluI palindrome. This explanation is not acceptable based on thermodynamic considerations. We propose another explanation that it was the result of self-priming starting from a small stem-loop (loop size $=4 \mathrm{nts}$, stem size $=2 \mathrm{bp}$ ) made of --CGUACGCG-3'.

Fullerton et al. [25] investigated the initiation reaction of RNA replication with Sapovirus (family with norovirus) replicase using $2259 \mathrm{nts}$ template of which 3'-terminal sequence is --UUGGAGCCAUUGCCCUCCAU-3'. They did not get a double length product and concluded the initiation by the primer-independent manner. In fact a potential 3'-terminal stem-loop has loop size eight (Additional file 5: Figure S5B (b)). This is not a small size and self-priming can hardly proceed. This results support our conclusion that when there is a small stem-loop (loop size 3-4, stem size 2) structure exists at 3'-terminus, the self-priming is the most preferable initiation reaction for an ssRNA template.

There were at least two amplification reaction products of the template Temp(GGG-GGG) (Figure 2 (ii); indicated with asterisk). Length of them was between 92 and $100 \mathrm{nts}$. If we consider a small stem-loop made with GG:UU stem, the length of self-priming product would be 91,88 , or 85 nts according to the loop size 5,8 , or 11 


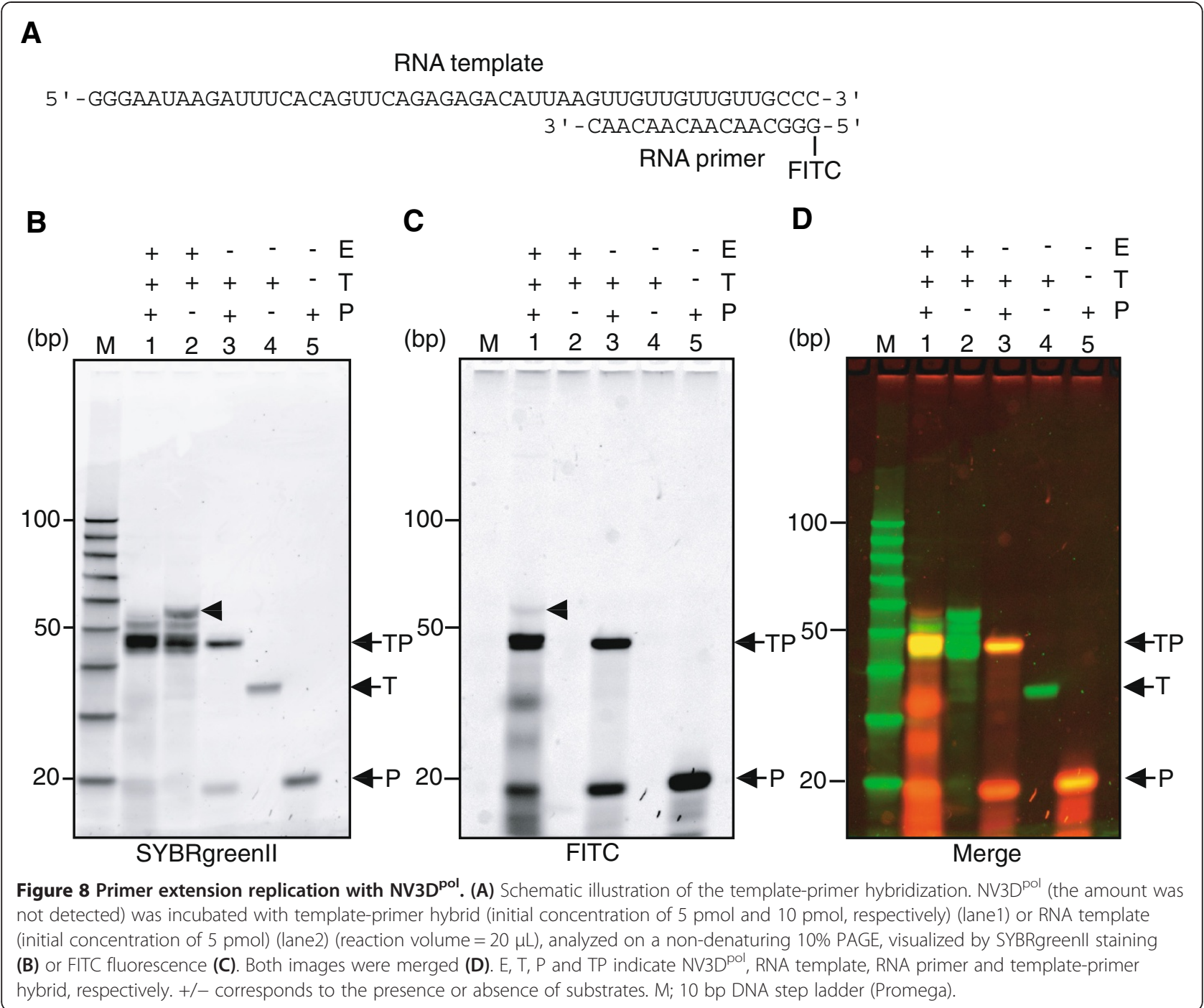

nts, respectively (Additional file 5: Figure S5A (ii)). Here we neglect loop size $2 \mathrm{nts}$, because it is very unstable because of the steric hindrance and the hairpin thermodynamics. They are probably originated from $\mathrm{C}$ and $\mathrm{CCC}$ addition to 3'-terminus with TNT activity of the enzyme. The products can make small stem-loops of GUUGGGGC and GGGGCCC which can make 94 nts and 99 nts product, respectively (Additional file 5: Figure S5A (ii)).

When there exists no small stem-loop structure at 3'-terminus and 3'-terminal sequence has C-stretch, the primer-independent initiation proceeds as shown in Figure 2B (i) and in the above mentioned case by Fullerton et al. [25]. Rohayem et al. [17] also pointed out that $\mathrm{NV} \mathrm{D}^{\text {pol }}$ prefers C-stretch at 3'-terminus for the replication initiation of the primer-independent manner. Importance of the $\mathrm{C}$-stretch was confirmed also the experiment using a long template of which sequence had no relation to norovirus genome. TD257-735g734c template showed six times larger amplification than
TD257-735 template. The former is a point mutant of the latter and the 3'-terminal sequence is --UCCCC and --UCCGC, respectively. They have no stable small stem loop at 3-terminus.

Although Rohayem et al. [17] indicated that NV3D ${ }^{\text {pol }}$ did not have an RNA synthesis activity on poly(A)-tail, we showed that $N V 3 D^{\text {pol }}$ initiated replication reaction on A-stretch at the 3'-terminus of TD257-735-A 22 template (Additional file 6: Figure S6). The RNA synthesis activity on A-stretch, however, was considerably lower than the case of TD257-735g734c template. Therefore, the initiation of primer-independent RNA replication reaction by $\mathrm{NV}_{3} \mathrm{D}^{\mathrm{pol}}$ prefers $\mathrm{C}$-stretch at the 3 '-terminus rather than A-stretch or poly(A)-tail. The differences between Rohayem's system and ours are the amino acids sequence of $\mathrm{NV} \mathrm{D}^{\mathrm{pol}}$, the length of poly(A)-tail, and enzyme concentration used. On the other hand, Fukushi et al. [19] already reported that NV3D ${ }^{\text {pol }}$ has the initiation activity of primer-independent RNA 
replication on poly(A)-tail. We supposed that the actual 3'-terminal sequence of RNA template used in Fukushi's work was -- $\left(\mathrm{A}_{30}\right) \mathrm{UGCGC}$.

It is reported that $\mathrm{Q} \beta$ replicase also favours $\mathrm{C}$-stretch. The initiation efficiency is high when 3'-terminal sequence is --CCC-3' or --CCA-3'. The efficient parasite RQ RNA has also the sequence --CCC-3'. By the way, we have not yet observed any parasite sequence in amplification with NV3D ${ }^{\text {pol }}$.

In the case of a blunt-end double-stranded RNA, the breathing of terminal double helical region makes the enzyme access to CC-stretch at 3'-terminus and start to replication in the primer-independent manner. To investigate whether $\mathrm{NV} \mathrm{D}^{\mathrm{pol}}$ initiates the replication to dsRNA which has a sticky-end preferably rather than the blunt-end [17], we prepared two kinds of RNA template, Temp(GGG-UCCCC) and Temp(GGG-UCCC) shown in Figure 6A. The secondary structure predicted by Mfold (Figure 6B) shows that the former mimics the terminal structure of dsRNA added a cytidine by TNT activity and the latter mimics the terminal structure of a blunt-end. As shown in Figure 6C, the band at about $50 \mathrm{bp}$ were amplified in the case of Temp(GGG-UCCC), but not in the case of Temp(GGG-UCCCC). This indicates that $\mathrm{NV} \mathrm{D}^{\mathrm{pol}}$ might initiate the replication from the blunt-end cytidines at the 3'-terminus preferably rather than from sticky-end cytidines. We investigated only about the addition of one cytidine. Although the addition of three cytidines was rare (Table 1), if dsRNA which has three cytidines overhung end were used, the initiation efficiency of replication might alter.

The initiation of the extension reaction of a long primer is not favourable for the enzyme as shown in Figure 8. Rohayem et al. [17] reported primer-dependent replication, but Fukushi et al. [19] reported their NV3D $^{\text {pol }}$ had no activity of primer extension. Our gene was a gift of Fukushi's group. Thus they might miss the faint band.

\section{Elongation reaction}

The self-priming reaction at a small stem-loop at 3'terminus is very active, but the extension activity of a long primer is very poor. Thus once the enzyme dissociates from the template-polymerizing chain hybrid, it is not easy for the enzyme to bind again. On the other hand as shown in Figure 5, the native state PAGE of the amplified product (479 bp) shows a single sharp band without smear. Thus we can draw the conclusion that the processivity of $\mathrm{NV} \mathrm{D}^{\mathrm{pol}}$ is very high.

$\mathrm{NV}^{\mathrm{p}}{ }^{\text {pol }}$ can perform also the chain dissociation replication smoothly as shown in Figure 5, even in the case of a template having GC-rich regions (Figure 7 and Additional file 8: Table S1(c)). The amplification products must be double stranded and amplification proceeded several times. The dissociated single stranded chain was converted to double strand in a primerindependent manner not so rapidly, because the band of ssRNA was visible on the non-denaturing PAGE (Additional file 3: Figure S3B).

\section{Termination reaction (TNT activity)}

Fukushi et al. [19] reported that their NV3D ${ }^{\text {pol }}$ had no TNT activity. Gene of NV3D ${ }^{\text {pol }}$ of our study is a gift from the laboratory in which their study was performed. Our results rather accords qualitatively with the report by Rohayem et al. [17,18]. They reported TNT activity of NV3D ${ }^{\text {pol }}$ added at least four cytidines, but we observed $-\mathrm{C},-\mathrm{CC}$ and $-\mathrm{CCC}$ addition. We also observed about half of products had no addition of $C$. The C-stretch (corresponding to $\mathrm{G}$ stretch on the template) at 3'-terminus in our replicate chain may affect the reduced number of addition. We also observe addition of A and $\mathrm{G}$, which accords with the reports by Rohayem et al. [18] and Fullerton et al. (Sapovirus $\left.3 \mathrm{D}^{\text {pol }}\right)[25]$.

It was also reported that Moloney murine leukemia virus (MMLV) adds some deoxycytidines at the 3'-terminus of reverse transcribed DNA, and switches the template utilizing this overhung $\mathrm{dC}$-stretch [26]. If $\mathrm{NV} \mathrm{D}^{\text {pol }}$ has the same template-switching activity as MMLV, the band corresponding to about 100 nts, observed in the replication reaction of Temp(GGG-GGG) RNA (Figure 2 (ii)), might be a denatured form of a tandem dimer dsRNA made through this activity rather than a double length dsRNA which was the product of replication from a self-priming product. Based on the fact that initiation efficiency of primer-independent manner at 3'-terminus GGG is significantly lower than self-priming with a small stem-loop, this explanation for $100 \mathrm{nts}$ band is not acceptable.

\section{Autocatalytic replication}

In the non-self-priming and primer-independent replication shown in Figure $3 \mathrm{~B}$ and Figure 7, the initial template ssRNA was amplified by 16 -fold and 6-fold by 240 min with $\mathrm{NV} \mathrm{D}^{\mathrm{pol}}$, respectively. In the former, the shape of amplification curve showed two phases; linear amplification phase up to $90 \mathrm{~min}$ and plateau phase near $240 \mathrm{~min}$, because the enzymatic activity of $\mathrm{NV} \mathrm{D}^{\mathrm{pol}}$ is limited by about $120 \mathrm{~min}$, as indicated in previous reports [18]. The autocatalytic replication should be realized in this case, but the exponential growth phase was not observed because the enzyme was not excess over the initial template and the linear phase can be explained by the full turnover of enzyme action. On the other hand, in the case of Figure 7, the enzyme was excess over the initial template. And the growth curve of RNA shows three phases; the initial nonlinear phase, the 
apparent linear phase and the plateau phase. The final phase was realized by the same reason as in the case of Figure 3B. The apparent linear phase was not originated from the full turnover of enzyme action because the enzyme was vastly excess over the existing RNA template. This apparent linear phase may be explained by attenuated exponential growth caused by deactivating replicase. The initial nonlinear phase may be explained two fold; the initial part of the exponential phase or the reaction curve of the two- (or multi-) step reaction. The isothermal amplification of RNA with $\mathrm{Q} \beta$ replicase also showed exponential growth of RNA under the similar condition [16].

\section{A possible model of molecular mechanism of the isothermal amplification of RNA with NV3D ${ }^{\text {pol }}$}

Rohayem et al. [17] showed a protein-primer model of norovirus genomic RNA replication in an infected host cell. Uridylated VPg protein binds to poly(A)-tail and begins replication starting from the $\mathrm{U}$. Our interest is not the viral infection process, but application to in vitro RNA amplification for an in vitro evolution. Based on the results of this study together with preceding reports, we propose the following model for the isothermal RNA amplification with NV3D ${ }^{\mathrm{pol}}$ in vitro (Figure 9) for templates having limited terminal sequences. NV3D ${ }^{\text {pol }}$ recognizes 3'-terminus -CCC of the template ssRNA and begins the synthesis of the complementary strand (without primer). Thus, in order to sustainable replication, 5 -terminus of the template must be -GGG. NV3D ${ }^{\text {pol }}$ prefers, however, a small stem-loop structure at the 3'terminus and begins RNA synthesis in the self-priming manner. Thus, both terminal sequences should not make such a small stem-loop. At the end of template synthesis, NV3D ${ }^{\text {pol }}$ sometimes adds several $C$ using its TNT activity. Thus, 3'-terminus of the replicated strand (RNA $(-))$ has a C-stretch just as the template $(\operatorname{RNA}(+))$ or sometimes a slightly longer $C$-stretch, because NV3D ${ }^{\text {pol }}$ recognizes the C-stretch at 3'-terminus of dsRNA, often accessible when it is breathing, and begins synthesis of the next generation strand using the chain dissociation replication activity.

\section{Conclusions}

In this study, it was confirmed that NV3D ${ }^{\text {pol }}$, prepared with cell-free protein synthesis system, was able to perform the isothermal amplification of RNA (even dsRNA) in vitro. But the initiation efficiency of replication is dependent on the 3'-terminal sequence. And we have to use the 3'-terminal sequence which does not make a small stem-loop, in order to avoid a parasitic selfpriming product. Thus, NV3D ${ }^{\text {pol }}$ can be used as an RNA replicase in in vitro RNA evolution with the RNA of special terminal sequences. $\mathrm{NV} 3 \mathrm{D}^{\mathrm{pol}}$, which is a single chain protein, is a candidate of a model protein in in vitro autonomous protein evolution in the form of an in vitro virus [27].

\section{Methods}

\section{Preparation of NV replicase (NV3D ${ }^{\text {pol }}$ )}

Plasmid pVL3Dwt (GenBank: AB039782 [19]) harbouring $\mathrm{NV} \mathrm{D}^{\mathrm{pol}}$ gene was kindly provided from BML Inc. PCR was performed with KOD-plus- DNA polymerase (TOYOBO) and the PCR products were purified with QIAquick PCR Purification Kit (QIAGEN). NV3D ${ }^{\text {pol }}$ gene was amplified from pVL3Dwt by PCR using prNV3Dstart(+) 5'-ATGGGAGGTGACGACAAGGGC$3^{\prime}$ and prNV3Dstop(-) 5'-TTATTCGACGCCATCTTC ATTCACA-3'. NV3D ${ }^{\text {pol }}$ gene was modified with the coding region for Strep-tag II sequence (WSHPQFEK) [21] using prNV3Dstart(+) and prNV3D-strep(-) 5'GCATCGACTCCTTACTTTTCAAACTGCGGATGGCTCCATTCGACGCCATCTTCATTC-3' (the sequence showed in italics indicates stop codon and Strep-tag II coding sequence) by PCR. At the downstream of the stop-codon, KpnI restriction site was added using prNV3Dstart(+) and prStrep-kpn1(-) 5'-GGGGTAC CTTACTTTTCAAACTGCGGATGGCTCC-3' (the sequence showed in italics indicates $K p n I$ cutting site) by PCR. Then the PCR product was digested with KpnI (TaKaRa) and integrated into the pTD1 expression vector (SHIMADZU Biotech) [23] according to the manufacture's instruction. The recombinant plasmid was named pTD-NV3D ${ }^{\text {pol }}$-strep. NV3D ${ }^{\text {pol }}$-strep expression construct DNA was amplified using prTD161-179 (5' GCAGATTGTACTGAGAGTG-3') and prTD845-827 (5'-GGAAACAGCTATGACCATG-3'), and transcribed in vitro with RiboMAX ${ }^{\mathrm{TM}}$ Large Scale RNA production system-T7 (Promega). The transcript, named NV3D ${ }^{\text {pol }}$ strep mRNA was purified with NICK column (GE Healthcare). NV3D ${ }^{\text {pol }}$-strep mRNA was translated with Transdirect insect cell cell-free protein synthesis kit (SHIMADZU Biotech) [28] according to the manufacture's instruction.

The translated product was purified with Strep-tactin Superflow plus (QIAGEN). The strep-tag II modified

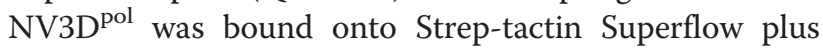
resin, pre-equilibrated with binding buffer $(50 \mathrm{mM}$ Tris- $\mathrm{HCl}$ [pH 8.0], $300 \mathrm{mM} \mathrm{NaCl}$ ). The bound protein was washed with the binding buffer and eluted with elution buffer $(50 \mathrm{mM}$ Tris- $\mathrm{HCl}[\mathrm{pH} 8.0], 300 \mathrm{mM} \mathrm{NaCl}$, and $2.5 \mathrm{mM}$ desthiobiotin (Sigma)). The eluted protein was then enriched and buffer-exchanged with buffer A $(25 \mathrm{mM}$ Tris- $\mathrm{HCl}$ [pH 8.0], $100 \mathrm{mM} \mathrm{NaCl}, 5 \mathrm{mM}$ $\mathrm{MgCl}_{2}$, and $1 \mathrm{mM} \beta$-mercaptoethanol) with Microcon YM-50 column (Millipore), and stored at $-80^{\circ} \mathrm{C}$. In the enrichment step using Microcon YM-50 column, bovine serum albumin (BSA) (TaKaRa) was used as a carrier 

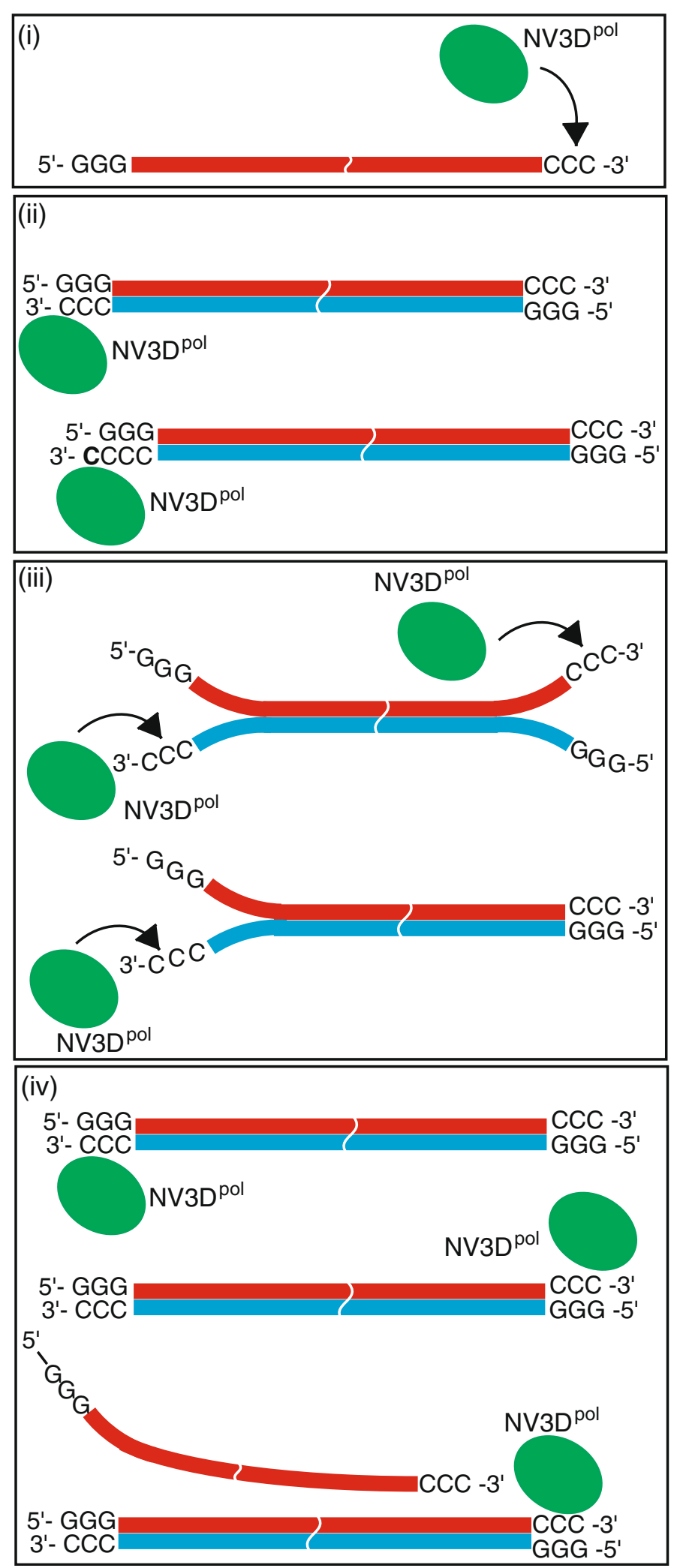

Figure 9 (See legend on next page.) 
(See figure on previous page.)

Figure 9 A model scheme of isothermal RNA amplification with NV3D ${ }^{\text {pol }}$. (i) NV3D ${ }^{\text {pol }}$ interacts to the CCC sequence at the $3^{\prime}$-terminus of RNA template $(\mathrm{RNA}(+))$, and (ii) made dsRNA (RNA(+) - RNA(-)). Sometimes the enzyme adds cytidine(s) at the 3'-terminus of RNA(-) by TNT activity. (iii) NV3D ${ }^{\text {pol }}$ interacts to the breathing CCC sequence. (iv) NV3D ${ }^{\text {pol }}$ replicates the dsRNA with displacing the RNA strand. The displaced RNA strand is recycled as a RNA template.

protein to avoid the non-specific adsorption of NV3D ${ }^{\text {pol }}$ to the column. The amount of NV3D ${ }^{\text {pol }}$-strep was quantified on sodium dodecyl sulfate poly-acrylamide gel electrophoresis (SDS-PAGE) referring a calibration curve with BSA.

\section{Preparation of RNA templates}

Sequences of RNA template used in this study were summarized in Additional file 9: Table S1 (a). Temp (GGG-CCC) DNA was generated by PCR using Temp (GGG-CCC) (5'-GCCAGTCGCCTGCAGTAATACGA CTCACTATAGGGAATAAGATTTCACAGTTCAGAGA GACATTAAGTTGTTGTTGTTGCCC-3') (underline indicates T7 $\Phi 6.5$ promoter sequence), prT7tempGGG + (5'-GCCAGTCGCCTGCAGTAATACGACTCACTA-3') and prTempCCC- (5' -GGGCAACAACAACAACTTAAT GTC-3'). Other DNA templates, Temp(GGG-GGG), Temp(GGG-CCA) Temp(GGG-UAC), Temp(GGG-UUC), Temp(GGG-UCC), Temp(GGG-GCCCC), Temp(GGG-U CCCC) and Temp(GGG-UCCC) DNA, were generated as same as Temp(GGG-CCC) DNA with the primer listed in Additional file 9: Table S1 (b). All PCR amplified DNAs were purified with QIAquick PCR Purification kit and in vitro transcribed with RiboMAX ${ }^{\mathrm{TM}}$ Large Scale RNA production system-T7. TD257-735 RNA were also in vitro transcribed from the PCR amplified DNA (the sequence was shown in Additional file 9: Table S1 (c)) using pTD1 [23], prTD161-179 and prTD735-714 (5'-GCGG ATAATATTTTGAACGACG-3'). TD257-735g734c RNA was made from TD257-735 by replacing $734^{\text {th }}$ guanosine to cytidine using prTD735-714g734c (5'-GGGGATAA TATTTTGAACGACG-3') in PCR. TD257-735-A 22 was made from TD257-735 by adding $22 \mathrm{nts}$ of adenine at the 3'-terminus using prTD757-733 (5'-TTTTTTTTTTTT TTTTTTTTTTGCG-3') in PCR. All RNA templates were purified on denaturing PAGE and quantified by measuring absorbance at $260 \mathrm{~nm}$.

\section{RNA primer}

RNA primer (5'-GGGCAACAACAACAAC-3') modified with FITC at the 5'-terminus was purchased from Japan Bio Service Inc.

\section{In vitro RNA replication or amplification with NV3D ${ }^{\text {pol }}$ strep}

RNA replication or amplification was performed with purified $\mathrm{NV}^{\mathrm{pol}}{ }^{\text {pol }}$-strep and in vitro-transcribed RNA template in a reaction buffer $(50 \mathrm{mM}$ Hepes- $\mathrm{KOH}$
[pH 7.0], $3 \mathrm{mM} \mathrm{MnCl}_{2}, 4 \mathrm{mM}$ DTT, $0.4 \mathrm{mM}$ rNTPs, and $40 \mathrm{U} / \mu \mathrm{L}$ of RNasin ribonuclease inhibitor plus (Promega)) at $30^{\circ} \mathrm{C}$. Reaction products were subjected to denaturing or non-denaturing PAGE followed by SYBRgreenII (Lonza) staining and visualized on Pharos Fx imager (Bio-Rad). Here, the non-denaturing PAGE was performed with 5 or $10 \%$ acrylamide, $0.625 \%$ bisacrylamide and TBE buffer at $20^{\circ} \mathrm{C}$. The denaturing PAGE was performed with $8 \mathrm{M}$ urea plus the same constituent of non-denaturing PAGE at $65^{\circ} \mathrm{C}$.

\section{Sequencing of 3'-terminus of amplified RNA}

To detect the addition of nucleotides at the 3'-terminus of replicated RNA (RNA(-)) by TNT activity of NV3D ${ }^{\text {pol }}$, we could not use a normal sequencing method using a primer which hybridizes 3'-terminal region of the sample RNA. Thus we sequenced the full length of RNA(-) applying the Y-ligation method [29], as follows (shown in Additional file 9: Figure S8). After the incubation of $240 \mathrm{~min}$ in the RNA amplification with NV3D ${ }^{\text {pol }}$-strep, the reaction solution was desalted with Micro bio-spin column 30 (Bio-Rad), and ligated with 5'-phosphorylated Y-adapter (5'-CAAAGGGAATAAGA TTTCACAGTTCAGAGCTTAGATAATACGACTCACT ATAGGGTTAAC-3') by Y-ligation method. The ligated product was hybridized with prT7g10SD-NV3D(-) $\left(5^{\prime}-\right.$ CCTTGTCGTCACCTCCCATGGATATATCTCCTTCT TAAAGTTAACCCTATAGTGAGTCGTATTA-3') and reverse transcribed with Avian myelobastosis virus (AMV) reverse transcriptase (Promega). The reverse transcribed product was purified on denaturing PAGE, and amplified by PCR using pr'TempCCC- and prSeq (5'-CCTTGTCGTC ACCTCCCA-3') as primers. TA cloning was performed with pGEM-T easy vector system (Promega). Sequencing was performed by Operon Inc. (Tokyo).

\section{Additional files}

Additional file 1: Figure S1. Amino acid sequence comparison of $N V 3 D^{\text {pol }}$ proteins used in Rohayem's report (A), in Fukushi's report (B) and in this report (C). The Amino acid sequence homologies between $(A)$ and (B), (B) and (C), (A) and (C) were 90.4, 99.2, 89.6\%, respectively. Amino acid substitutions were indicated in bold letters.

Additional file 2: Figure S2. Primer-independent RNA amplification reaction of Temp(GGG-CCC) RNA with NV3D ${ }^{\text {pol }}$ under the excess BSA condition (lane 3 and 4). Temp(GGG-CCC) RNA (5 pmol) was incubated with $\mathrm{NV} \mathrm{D}^{\mathrm{pol}}$ (the amount was not detected) and sampled at 0 and $120 \mathrm{~min}$. In the case of excess BSA +, 500 ng of BSA was added to the standard reaction mixture (BSA -). M1; 10 bp DNA step ladder (Promega). M2; DynaMarker dsRNA ladder (BioDynamics Laboratory Inc.). Ref.; Temp(GGG-CCC) RNA. 
Additional file 3: Figure S3. Supplements to Figure 2. (A) Quantification of amplification of 50 nts ssRNA in Figure 2B (8M urea denaturing 10\% PAGE). Closed circle; (i) Temp (GGG-CCC), closed diamond; (ii) Temp (GGG-GGG), closed triangle; (iii) Temp (GGG-CCA), closed square; (iv) Temp (GGG-UAC). (B) Non-denaturing PAGE. NV3D ${ }^{\text {pol }}$ (5 pmol) was incubated with (i) Temp (GGGCCC), (ii) Temp (GGG-GGG), (iii) Temp (GGG-CCA) or (iv) Temp (GGG-UAC) (5 pmol each), and sampled at 0,60, 120, 180 min respectively (reaction volume $=20 \mu \mathrm{L}$ ), which is the same reactions shown in Figure 2, Each reaction aliquots were analysed on a non-denaturing 10\% PAGE, and imaged with Fx imager after SYBRgreenll staining. M; 10 bp DNA step ladder marker (Promega). Lot of the enzyme was different from the experiment of Figure 2.

Additional file 4: Figure S4. S1 nuclease treatment of the amplification product of Temp(GGG-CCC). Temp(GGG-CCC) RNA (5 pmol) and NV3D pol (the amount was not detected) were incubated at $30^{\circ} \mathrm{C}$ for $120 \mathrm{~min}$. The reaction was stopped with adding EDTA, followed by PCI (phenol/ chloroform/isoamylalchol $=25: 24: 1$ ) and CIA (chloroform/isoamylalchol $=24: 1$ ) extraction, and ethanol precipitation. Then the pellet was resuspended with $1 \times \mathrm{S} 1$ nuclease buffer (TaKaRa) and incubated with $13.5 \mathrm{U} / \mathrm{ML}$ of $\mathrm{S} 1$ nuclease (TaKaRa) at $37^{\circ} \mathrm{C}$ for $15 \mathrm{~min}$. Each aliquot was added with EDTA to stop the reaction, and analyzed on an $8 \mathrm{M}$ urea denaturing 10\% PAGE (A) or a non-denaturing 10\% PAGE (B), visualized by SYBRgreenll staining. M1; 10 bp step DNA ladder (Promega). M2; DynaMarker dsRNA ladder (BioDynamics Laboratory Inc.). White headarrows indicated in lane 2 were the nucleic acids from cell-free protein synthesis system (e.g. tRNAs).

Additional file 5: Figure S5. Potential small stem-loop structures of 3'-terminus of RNA templates. (A) 3'-terminal sequence and potential small stem-loop structure of Temp(GGG-GGG) (ii), Temp(GGG-CCA) (iii) and Temp(GGG-UAC) (iv). Asterisks indicate the hybridization points between 3 '-terminus. In (ii), the potential small stem-loop in the case of addition of 1 - 3 cytidine(s) on $3^{\prime}$-terminus were shown. (B) Potential small stem-loop structures of 3 '-terminal sequence used in the previous reports ((a); [20,22], (b); [25]).

Additional file 6: Figure S6. Effect of poly(A)-tail for the initiation efficiency of RNA replication. TD257-735- $A_{22}$ RNA (0.4 pmol) were incubated with NV3D $\mathrm{D}^{\mathrm{pol}}$ (4 pmol) (reaction volume $=20 \mu \mathrm{L}$ ) and analyzed on a non-denaturing 5\% PAGE. M; 100 bp DNA ladder marker (Promega). In our PAGE condition, dsDNA 400 bp marker (Promega) corresponds to dsRNA 430bp marker (BioDynamics Laboratory Inc.).

Additional file 7: Figure S7. Supplement to Figure 8. Denaturing PAGE analysis. Experimental conditions are the same as in Figure 8, except the final analysis step, namely, analyzed on an $8 \mathrm{M}$ urea denaturing $10 \%$ PAGE, visualized by SYBRgreenll staining (A) or FITC fluorescence (B). Both images were merged (C). Arrowheads indicate the elongate primer (lane 1) and the primer-independent RNA synthesis product (lane 2), respectively. $E, T, P$ and TP indicate NV3D ${ }^{\mathrm{pol}}$, RNA template, RNA primer and template-primer hybrid, respectively. +/- corresponds to the presence or absence of substrates. $\mathrm{M}_{i} 10$ bp DNA step ladder (Promega).

Additional file 8: Table S1. Sequences of RNA templates (a), DNA oligomers (b) used in this work. DNA sequence of 161-757 region in PTD1 (c). Underline indicates T7 $\varphi 6.5$ promoter sequence.

Additional file 9: Figure S8. Schematic illustration of sample preparation for the $3^{\prime}$-terminus sequencing of RNA. As described in Materials and Methods, the reaction procedure is as follows; (1) the replicated RNA (RNA (-), shown in red) was ligated with an adapter DNA (shown in blue) hybridized at the 3'-terminal region of RNA(-) by the Y-ligation method. (2) The ligation product was reverse-transcribed with RT primer (green arrow) to CDNA, (3) and the CDNA was amplified by $\mathrm{PCR}$, cloned and sequenced.

\section{Competing interests}

The authors declare that they have no competing interests.

\section{Authors' contributions}

$\mathrm{HA}$ and $\mathrm{YH}$ designed the study, analyzed the data and wrote the paper. HA performed the experiments. NN, MS and KN analyzed the data. All authors contributed to the manuscript and have read and approved the final manuscript.

\section{Acknowledgements}

We thank BML Inc. for providing us the plasmid pVL3Dwt [19] harbouring NV3D ${ }^{\text {pol }}$ gene. We thank Drs. Manish Biyani and Shingo Ueno for helpful discussions.

\section{Author details}

${ }^{1}$ Graduate School of Science and Engineering, Saitama University, 255 Shimo-Okubo, Sakura-ku, Saitama 338-8570, Japan. ${ }^{2}$ Innovative Research Organization, Saitama University, 255 Shimo-Okubo, Sakura-ku, Saitama 338-8570, Japan.

Received: 30 January 2013 Accepted: 17 September 2013 Published: 9 October 2013

\section{References}

1. Haruna I, Spiegelman S: Autocatalytic synthesis of viral RNA in vitro. Science 1965, 150:884-886.

2. Biebricher CK, Eigen M, Luce R: Product analysis of RNA generated de novo by Q $\beta$ replicase. J Mol Biol 1981, 148:369-390.

3. Biebricher CK, Eigen $M$, Luce R: Kinetic analysis of template-instructed and de novo RNA synthesis by $Q \beta$ replicase. J Mol Biol 1981, 148:391-410.

4. Guatelli JC, Whitfield KM, Kwoh DY, Barringer KJ, Richman DD, Gingeras TR: Isothermal, in vitro amplification of nucleic acids by a multienzyme reaction modelled after retroviral replication. Proc Natl Acad Sci USA 1990, 87:1874-1878

5. Compton J: Nucleic acid sequence-based amplification. Nature 1991, 350:91-92.

6. Breaker RR, Joyce GF: Emergence of a replicating species from an in vitro RNA evolution reaction. Proc Natl Acad Sci USA 1994, 91:6093-6097.

7. Mills DR, Peterson Rl, Spiegelman S: An extracellular darwinian experiment with a self-duplicating nucleic acid molecule. Proc Natl Acad Sci USA 1967, 58:217-224.

8. Ekland EH, Bartel DP: RNA-catalysed RNA polymerization using nucleoside triphosphates. Nature 1996, 382:373-376.

9. Johnston WK, Unrau PJ, Lawrence MS, Glasner ME, Bartel DP: RNA-catalyzed RNA polymerization: accurate and general RNA-templated primer extension. Science 2001, 292:1319-1325.

10. Nemoto $N$, Miyamoto-Sato $E$, Husimi $Y$, Yanagawa $H$ : In vitro virus: Bonding of mRNA bearing puromycin at the 3 '-terminal end to the C-terminal end of its encoded protein on the ribosome in vitro. FEBS Lett 1997, 414:405-408.

11. Roberts RW, Szostak JW: RNA-peptide fusions for the in vitro selection of peptides and proteins. Proc Natl Acad Sci USA 1997, 94:12297-12302.

12. Fodor SP, Read JL, Pirrung MC, Stryer L, Lu AT, Solas D: Light-directed, spatially addressable parallel chemical synthesis. Science 1991, 251:767-773.

13. Blumenthal T, Carmichael GG: RNA replication: function and structure of Qß-replicase. Annu Rev Biochem 1979, 48:525-548.

14. Barrera I, Schuppli D, Sogo JM, Weber H: Different mechanisms of recognition of bacteriophage $Q \beta$ plus and minus strand RNAs by $Q \beta$ replicase. J Mol Biol 1993, 232:512-521.

15. Munishkin AV, Voronin LA, Ugarov VI, Bondareva LA, Chetverina HV, Chetverin AB: Efficient templates for $\mathrm{Q} \beta$ replicase are formed by recombination from heterologous sequences. J Mol Biol 1991, 221:463-472.

16. Urabe H, Ichihashi N, Matsuura T, Hosoda K, Kazuta Y, Kita H, Yomo T: Compartmentalization in a water-in-oil emulsion repressed the spontaneous amplification of RNA by Q $\beta$ replicase. Biochemistry 2010, 49:1809-1813.

17. Rohayem J, Robel I, Jäger K, Scheffler U, Rudolph W: Protein-primed and de novo initiation of RNA synthesis by norovirus $3 D^{\text {pol }}$. J Virol 2006, 80:7060-7069

18. Rohayem J, Jäger K, Robel I, Scheffler U, Temme A, Rudolph W: Characterization of norovirus $3 \mathrm{D}^{\mathrm{pol}} \mathrm{RNA}$-dependent RNA polymerase activity and initiation of RNA synthesis. J Gen Virol 2006, 87:2621-2630.

19. Fukushi S, Kojima S, Takai R, Hishino BF, Oka T, Takeda N, Katayama K, Kageyama T: Poly(A)- and primer-independent RNA polymerase of norovirus. J Virol 2004, 78:3889-3896.

20. Belliot G, Sosnovtsev SV, Chang K, Babu V, Uche U, Arnold JJ, Cameron CE, Green KY: Norovirus proteinase-polymerase and polymerase are both active forms of RNA-dependent RNA polymerase. J Virol 2005, 79:2393-240. 
21. Skerra A, Schmidt TGM: Use of the Strep- tag and streptavidin for detection and purification of recombinant proteins. Methods Enzymol 2000, 326:271-304.

22. Wei L, Huhn JS, Mory A, Pathak HB, Sosnovtsev SV, Green KY, Cameron CE: Proteinase-polymerase precursor as the active form of ferine calicivirus RNA-dependent RNA polymerase. J Virol 2001, 75:1211-1219.

23. Suzuki T, Ito M, Ezure T, Kobayashi S, Shikata M, Tanimizu K, Nishimura O: Performance of expression vector, pTD1, in insect cell-free translation system. J Biosci Bioeng 2006, 102:69-71.

24. Zuker M: Mfold web server for nucleic acid folding and hybridization prediction. Nucleic Acids Res 2003, 31:3406-3415.

25. Fullerton SWB, Blaschke M, Coutard B, Gebhardt J, Gorbalenya A, Canard B, Tucker PA, Rohayem J: Structural and functional characterization of sapovirus RNA-dependent RNA polymerase. J Virol 2007, 81:1858-1871.

26. Wellenreuther R, Schupp I, The German cDNA Consortium, Poustka A, Wiemann S: SMART amplification combined CDNA size fractionation in order to obtain large full-length clones. BMC Genomics 2004, 5:36.

27. Tabuchi I, Soramoto S, Nemoto N, Husimi Y: An in vitro DNA virus for in vitro protein evolution. FEBS Lett 2001, 508:309-312.

28. Ezure T, Suzuki T, Higashide S, Shintani E, Endo K, Kobayashi S, Shikata M, Ito M, Tanimizu K, Nishimura O: Cell-free protein synthesis system prepared from insect cells by freeze-thawing. Biotechnol Prog 2006, 22:1570-1577.

29. Nishigaki K, Taguchi K, Kinoshita Y, Aita T, Husimi Y: Y-ligation: an efficient method for ligating single-stranded DNAs and RNAs with T4 RNA ligase. Mol Divers 1998, 4:187-190.

doi:10.1186/1472-6750-13-85

Cite this article as: Arai et al:: Characterization of Norovirus RNA

replicase for in vitro amplification of RNA. BMC Biotechnology 2013 13:85.

\section{Submit your next manuscript to BioMed Central and take full advantage of:}

- Convenient online submission

- Thorough peer review

- No space constraints or color figure charges

- Immediate publication on acceptance

- Inclusion in PubMed, CAS, Scopus and Google Scholar

- Research which is freely available for redistribution 